\title{
Fuzzy Decision Support System for ABC University Student Admission Selection
}

\author{
Muchtar Ali Setyo Yudono ${ }^{1}$, "Riyan Mirdan Faris ${ }^{2}$, Aryo De Wibowo ${ }^{3}$, \\ Muhammad Sidik ${ }^{4}$, Falentino Sembiring ${ }^{5}$, Sankan Fahmi Aji ${ }^{6}$ \\ ${ }^{I}$ Nusa Putra University, Sukabumi, Indonesia \\ ${ }^{2}$ Nusa Putra University, Sukabumi, Indonesia \\ ${ }^{3}$ Nusa Putra University, Sukabumi, Indonesia \\ ${ }^{4}$ Nusa Putra University, Sukabumi, Indonesia \\ ${ }^{5}$ Nusa Putra University, Sukabumi, Indonesia \\ ${ }^{6}$ Nusa Putra University, Sukabumi, Indonesia \\ "Corresponding author. E-mail: riyan.mirdan@nusaputra.ac.id
}

\begin{abstract}
New Student Admission (PMB) is a pattern for selecting prospective students. Every year, every University conducts PMB selection, and new student admissions are divided into numerous tracks: the Independent Path. The Basic Competency Exam, TOEFL Prediction, and interviews are commonly used in this selection process. So far, the registrant data has been manually sorted in the selection process. A system that can help determine prospective new students will be required since many student data will be picked for PMB. Because of the system's assistance, universities can make the selection process more effective. The method used in this study to implement a PMB decision system is Fuzzy Mamdani. The method in this study has a sequence of stages: first doing fuzzification, second using inference evaluation rules that have been determined, and finally, defuzzification to get the final results of the calculations. This system was tested by comparing the system's results to the actual results obtained according to the design. The system testing results received a 96 percent approval rating. As a result, the University's new student admissions system can be used to help streamline the formerly manual selection process.
\end{abstract}

Keywords: Corporate Social Responsibility, ROA, Tobin's Q, Financial Performance, Marketing Cost.

\section{INTRODUCTION}

PMB (Prospective Student Admission) is a pattern of selection for prospective students [1], [4]. PMB selection is usually made once a year at each university. Prospective students of ABC University must pass several stages in the selection process for new admissions, including the Basic Competency Exam, which assesses basic knowledge and psychology, the TOEFL Prediction, which assesses basic English skills; and the interview, which assesses students' interests. Students that might be interested in $\mathrm{ABC}$ University are projected to be able to recruit students who match these requirements [5], [6].

Due to many registered participants, either through the accomplishment road or the standard route, New Student Admission (PMB) is a long and complicated process, resulting in a score tie or similarity amongst registrants. Furthermore, because whether a student is eligible or not to be accepted at a university is unclear, there are many potentials for errors in making new student admission decisions, and it is anticipated that they would admit prospective new students who are not accepted. Achieve the desired standard, or even pass new students with the desired standard. ABC University's new student selection committee must complete this task to reduce decision-making errors. For this reason, it is necessary to have a PMB decision support system that can help overcome all these problems, using fuzzy logic [1], [5], [7], [10]. Fuzzy has a meaning that is fuzzy or vague [11], in which this system can manage data to determine the performance results of employees [12], [13]. It will be adequate to use fuzzy logic to determine the best decision to answer this research [14]. 
The logic is a little hazy. Published a paper on this issue in 2014 called "Implementation of Fuzzy Logic Algorithms in the selection Process for New Student Admissions (Applied to the Kotabaru Polytechnic)" [15].

In this study, two input variables are employed: the written test results and the interview test score, which will result in two outcomes, Pass and Fail. According to the findings of this study, a computerized-based new admissions information system can help the administration determine PMB graduation.

Research on decision making using fuzzy logic, such as the paper "Prediction of Landing and Takeoff of Aircraft based on the Weather Using Fuzzy Logic" [16], which considers whether or not an airport is suitable for landing or flying an airplane. With shifting weather circumstances, this study used the Mamdani fuzzy logic method to analyze three parameters: wind speed, wind direction, and visibility, and found that certain weather conditions are appropriate, cautious, and not suitable for an airplane landing or takeoff on an airport runway.

This project intends to create a simulation of a decision-making assistance system for New Student Admissions at a University using the results of the journals mentioned above. The Mamdani fuzzy logic intelligent system was used in this study to describe the problems associated with New Student Admission by using the Basic Competency Exam, TOEFL Prediction, and interviews as PMB parameters that contain uncertainty that can be used to determine whether a student passes or fails PMB at a university, because fuzzy logic intelligent systems can describe, know, and model human thought processes and desirability. PMB decisionmaking should be more accurate, effective, and efficient thanks to the fuzzy logic process, including fuzzification, inference, and defuzzification.

\section{RESEARCH METHOD}

It is necessary to create a decision support system using the Mamdani fuzzy logic method, which has three variables: The Basic Competency Exam, TOEFL Prediction, and interviews, to assess the feasibility of a student being accepted at a university be more effective and efficient. Based on prior research on the feasibility of a student being accepted at a university, this variable has a relationship between data factors and the choice to assess the feasibility of a student being admitted. A fuzzy logic system will process all variables in each criterion. Fuzzy logic is seen as a helpful tool for dealing with ambiguity and ambiguity, and it has been used successfully in a variety of industries, including engineering and management [17]. Fuzzification, inference, and defuzzification are the three steps of the fuzzy logic system. The fuzzification process is a mapping procedure that uses the membership function of fuzzy sets to map input values (input crisp) from a controlled system. By analyzing current rules, all combinations of factors or parameters will be compared, resulting in a determination of a student's eligibility to be accepted into a university.

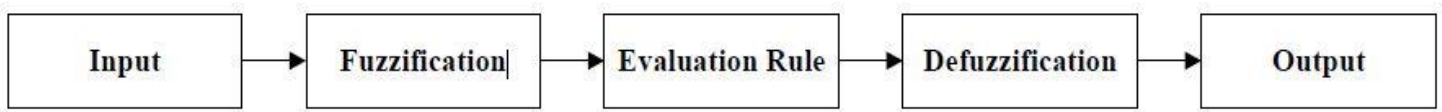

Figure. 1. Designing a Decision Support System for New Student Admissions at ABC University using Fuzzy Logic

Figure 1 shows a diagram system and a thorough description of how ABC University used fuzzy logic to develop a decision support system for new student admissions. The data used in this study for fuzzy logic was derived from earlier studies. Each input data variable's crisp value is processed using fuzzy logic (fuzzification). The defuzzification procedure takes as input a fuzzy set formed by the composition of fuzzy rules, with the resulting decision being a number in the fuzzy set's domain. Furthermore, the process of reading or executing the existing rules is carried out using the outcomes of the fuzzification.

\section{1. fuzzification}

A linguistic value and a fuzzy variable based on a fuzzy set are assigned to each fuzzy. This fuzzy set is a collection of data categorized as fuzzy variables and has specified restrictions. The fuzzy set is a study that combines objective data. Figures 2 through 4 offer graphical representations of linguistic qualities. 
Table 1. Linguistic variables and categories of each parameter

\begin{tabular}{|c|c|c|c|}
\hline No & Variable & \multicolumn{2}{|c|}{ Criteria } \\
\hline \multirow{3}{*}{1} & \multirow{3}{*}{$\begin{array}{c}\text { Competency } \\
\text { Exam }\end{array}$} & $200-300$ & Low \\
\hline & & $280-600$ & Medium \\
\hline & & $550-800$ & High \\
\hline \multirow{3}{*}{2} & \multirow{3}{*}{ TOEFL Prediction } & $200-425$ & Low \\
\hline & & $400-500$ & Medium \\
\hline & & $475-677$ & High \\
\hline \multirow{3}{*}{3} & \multirow{3}{*}{ Interview } & $0-55$ & Low \\
\hline & & $50-80$ & Medium \\
\hline & & $75-100$ & High \\
\hline \multirow{2}{*}{4} & \multirow{2}{*}{ Decision } & 0 & Accepted \\
\hline & & 1 & Rejected \\
\hline
\end{tabular}

1) Basic Competency Exam

The LOW, MEDIUM and HIGH fuzzy sets define the Basic Competency Exam variable. A trapezoidal curve for the LOW fuzzy set, a triangular curve for the MEDIUM fuzzy set, and a trapezoidal curve for the HIGH fuzzy set represent the Basic Competency Exam value variable. Figure 2 shows the fuzzy set image for the Basic Competency Exam variable.

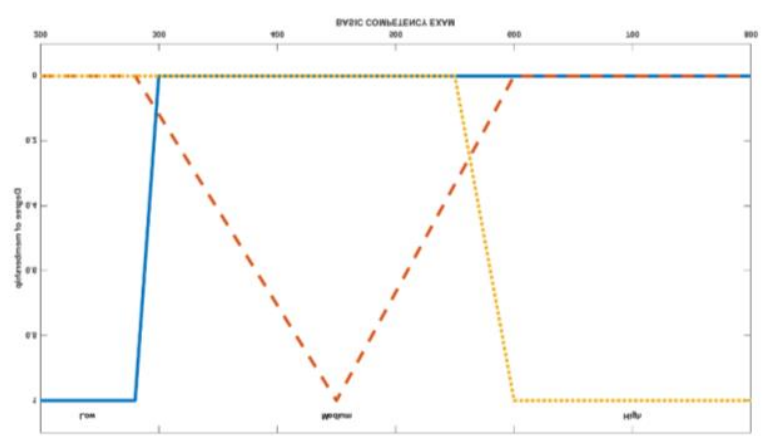

Figure 2. Fuzzy Set of Variables Basic Competency Exam

\section{2) TOEFL Prediction}

Three fuzzy sets, LOW, MEDIUM, and HIGH, define the TOEFL Prediction variable. A trapezoidal curve is used for the LOW fuzzy set, for the MEDIUM fuzzy set, a triangular curve is used, and for the HIGH fuzzy set, a trapezoidal curve is used. Figure 3 depicts the image of the fuzzy set for the TOEFL Prediction variable.

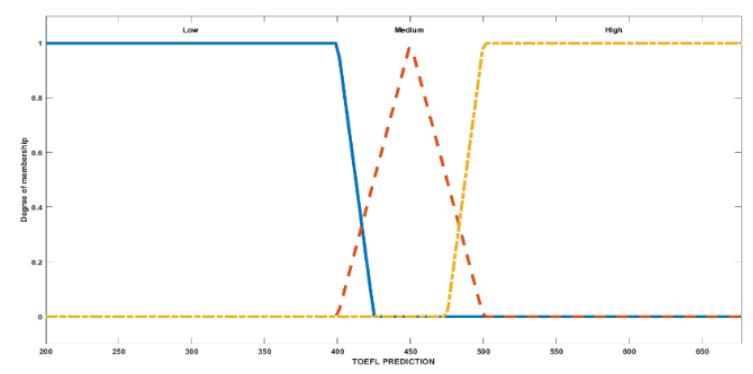

Figure 3. TOEFL Prediction Variable Fuzzy Set

3) Interview

Three fuzzy sets, LOW, MEDIUM, and $\mathrm{HIGH}$, were used to define interview variables. A trapezoidal curve is used for the LOW fuzzy set, for the MEDIUM fuzzy set, a triangular curve is used, and for the HIGH fuzzy set, a trapezoidal curve is used. Figure 4 depicts the image of the fuzzy set for the Interview variable.

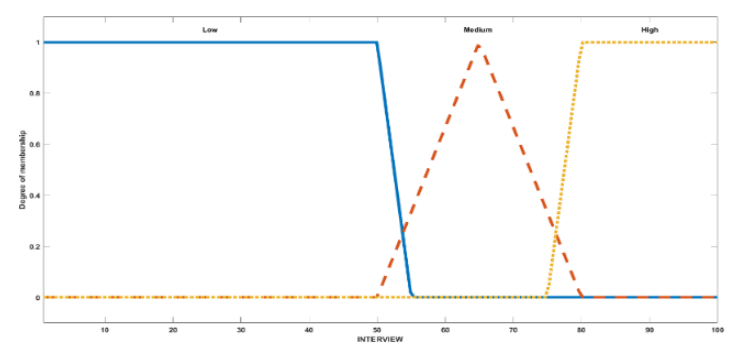

Figure 4. Fuzzy Set of Interview Variables

\subsection{Evaluation Rules}

Interview Variables That Are not Clearly Defined. This assessment method was created using a rule approach and correlation computations to determine the importance of variables. As a result of the process, the assessment rules were reduced to 30 rules. Table 2 contains references and instructions for determining evaluation norms. 
Table 2. Evaluation rules

\begin{tabular}{|c|c|c|c|c|}
\hline No & Basic Competency Exam & TOEFL Prediction & Interview & Decision \\
\hline 1 & Medium & Medium & Low & Rejected \\
\hline 2 & Medium & High & Medium & Accepted \\
\hline 3 & Medium & Low & Low & Rejected \\
\hline 4 & Medium & High & High & Accepted \\
\hline 5 & Medium & Medium & Medium & Accepted \\
\hline 6 & Medium & Medium & High & Accepted \\
\hline 7 & Medium & High & Medium & Accepted \\
\hline 8 & Medium & Medium & Medium & Accepted \\
\hline 9 & High & Medium & High & Accepted \\
\hline 10 & High & Medium & High & Accepted \\
\hline 11 & High & Low & Medium & Rejected \\
\hline 12 & Medium & Medium & High & Accepted \\
\hline 13 & Medium & High & Medium & Accepted \\
\hline 14 & Medium & Medium & High & Accepted \\
\hline 15 & Medium & Low & Medium & Rejected \\
\hline 16 & High & Low & High & Rejected \\
\hline 17 & Medium & Low & Low & Rejected \\
\hline 18 & Medium & Medium & High & Accepted \\
\hline 19 & Medium & Medium & Low & Rejected \\
\hline 20 & Medium & High & High & Accepted \\
\hline 21 & Medium & High & Medium & Accepted \\
\hline 22 & Medium & High & Low & Rejected \\
\hline 23 & Medium & Medium & High & Accepted \\
\hline 24 & Medium & High & Medium & Accepted \\
\hline
\end{tabular}




\begin{tabular}{|c|c|c|c|c|}
25 & Low & High & Medium & Rejected \\
\hline 26 & Medium & Medium & High & Accepted \\
\hline 27 & Medium & Low & High & Rejected \\
\hline 28 & Medium & High & High & Accepted \\
\hline 29 & Medium & Medium & High & Accepted \\
\hline 30 & Medium & Medium & Medium & Accepted \\
\hline
\end{tabular}

\subsection{Defuzzification}

It is used to find fuzzy membership during the defuzzification process. Each variable, such as the Basic Competency Exam, TOEFL Prediction, and interviews, was considered. Three variables will be obtained as a result of a fuzzy logic evaluation of the output level of a combination of variables. Accepted and rejected output levels are the two types of output levels.

\section{RESULTS AND ANALYSIS}

The results of fuzzy logic computations are reported in this chapter. Calculations were performed using data from 30 students. The criteria from the computation results are then compared to the rule's actual probability data. The data used in this investigation and the actual and system probability results are listed in Table 3 .

Table 3. Evaluation rules

\begin{tabular}{|c|c|c|c|c|c|}
\hline No & $\begin{array}{c}\text { Basic Competency } \\
\text { Exam }\end{array}$ & TOEFL Prediction & Interview & $\begin{array}{c}\text { Decision by } \\
\text { System }\end{array}$ & $\begin{array}{c}\text { Decision by } \\
\text { Rule }\end{array}$ \\
\hline 1 & 375 & 463 & 45 & Rejected & Rejected \\
\hline 2 & 400 & 487 & 65 & Accepted & Accepted \\
\hline 3 & 425 & 330 & 45 & Rejected & Rejected \\
\hline 4 & 450 & 478 & 80 & Accepted & Accepted \\
\hline 5 & 380 & 465 & 70 & Accepted & Accepted \\
\hline 6 & 500 & 445 & 90 & Accepted & Accepted \\
\hline 7 & 430 & 489 & 70 & Accepted & Accepted \\
\hline 8 & 480 & 462 & 70 & Accepted & Accepted \\
\hline 9 & 575 & 471 & 90 & Accepted & Accepted \\
\hline 10 & 600 & 453 & 90 & Accepted & Accepted \\
\hline 11 & 625 & 375 & 70 & Rejected & Rejected \\
\hline
\end{tabular}




\begin{tabular}{|c|c|c|c|c|c|}
\hline 12 & 370 & 400 & 80 & Rejected & Accepted \\
\hline 13 & 300 & 500 & 70 & Accepted & Accepted \\
\hline 14 & 350 & 473 & 75 & Accepted & Accepted \\
\hline 15 & 325 & 350 & 70 & Rejected & Rejected \\
\hline 16 & 600 & 360 & 79 & Rejected & Rejected \\
\hline 17 & 375 & 375 & 30 & Rejected & Rejected \\
\hline 18 & 425 & 450 & 76 & Accepted & Accepted \\
\hline 19 & 500 & 425 & 40 & Rejected & Rejected \\
\hline 20 & 525 & 525 & 80 & Accepted & Accepted \\
\hline 21 & 300 & 550 & 60 & Accepted & Accepted \\
\hline 22 & 325 & 475 & 40 & Rejected & Rejected \\
\hline 23 & 375 & 470 & 85 & Accepted & Accepted \\
\hline 24 & 350 & 520 & 55 & Accepted & Accepted \\
\hline 25 & 250 & 510 & 60 & Rejected & Rejected \\
\hline 26 & 350 & 470 & 75 & Accepted & Accepted \\
\hline 27 & 375 & 375 & 80 & Rejected & Rejected \\
\hline 28 & 400 & 475 & 85 & Accepted & Accepted \\
\hline 29 & 400 & 450 & 90 & Accepted & Accepted \\
\hline 30 & 450 & 425 & 60 & Accepted & Accepted \\
\hline
\end{tabular}

The output results validate the fuzzy logic data results in MATLAB according to the requirements in Table 3. The outcomes of a student's eligibility decision to be accepted at a university differ between the output according to the criteria and the output of fuzzy logic utilizing the MATLAB system, as shown in Table 3 columns indicated in yellow. 1 data has different results with the output according to the criteria for the decision on the possibility of a student being accepted at a university with fuzzy logic using MATLAB.
The results produced from the 30 data sets processed with fuzzy logic in MATLAB are comparable. There is a tiny change in the production, but it is not substantial. The term "not too significant" refers to the fact that the difference in results achieved using MATLAB is simply a little inaccurate. The outcomes of the decisions according to the criteria that have been determined from the results of the decisions using MATLAB are the same in 29 data. Because the adequacy of the computation data makes little difference in the inference process, this occurs. 
The try-and-error process and the results of interviews with the new student admissions committee that tackles this topic are still used to translate the output numbers from MATLAB into linguistic values in the decision on a student's eligibility to be accepted at a university. Because there is only one error, the outcomes of data processing for deciding on the possibility of a student being accepted at the university using the fuzzy logic method employing MATLAB software are reasonably good. The MATLAB toolbox is more complicated in terms of calculation, and the membership function determines the accuracy of fuzzy output for each parameter and the toolbox's rules. Because the results of the comparison 2 data differ from the actual data, the fuzzy logic accuracy percentage is calculated as follows:

$$
\begin{aligned}
& \frac{\text { Many data the same }}{\text { Total Data }} \times 100 \% \\
& \frac{29}{30}=96 \%
\end{aligned}
$$

The computer-based decision-making process in this study is additionally aided by a user interface (UI) [18]. In the selection process, Figure 4 shows the user interface for determining whether a student is accepted or denied (PMB). The University's selection committee (PMB) initially enters the parameter values of the results from the Basic Competency Exam, TOEFL Prediction, and interviews. The outcomes of this decision will be examined later, and if the University's policy changes, the decision will be re-planned [19]. Each University, of course, has its own admissions procedure. It is intended that this study would serve as a model for future research for researchers [20].

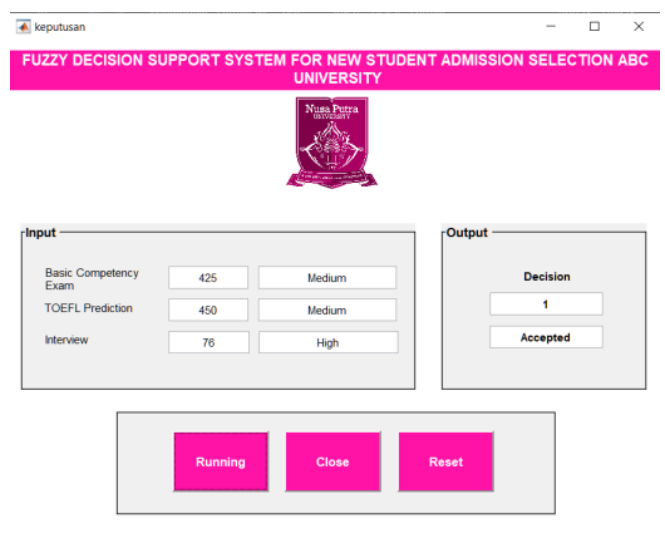

Figure 5. User Interface of Student Admission Selection

\section{CONCLUSION}

The proposed fuzzy logic for an intelligent decision support system to assess a student's eligibility for admission to the University is presented in this research. The Basic Competency Exam, TOEFL Prediction, and interviews are among the elements that can impact the decision to assess a student's ability to be accepted to the University. The decision to determine a student's eligibility for admission to the University is separated into two categories: acceptance and rejection. The choice to assess the likelihood of a student being accepted at the University is made using fuzzy logic, which is then compared to the outcomes of specified criteria. There are 30 data points gathered from prior research. With a percentage of 96 percent, 29 data have the same outcomes between the results of the decisions according to the criteria that have been determined from the results of decisions using MATLAB. This difference is insignificant because of the gap between actual and system probability. As a result, the fuzzy logic system appears to be highly effective.

\section{REFERENCES}

[1] M. H. Rohman and R. Yunitarini, "New Student Admission Decision Support System Using Fuzzy Logic Method Sugeno Model," Rekayasa, vol. 8, no. 1, pp. 9-21, 2015.

[2] M. S. Bunga and E. Ismantohadi, "WebBased and SMS-Based Student Admission Decision Support With New Fuzzy Associative Memory Method (Case Study: Indramayu Polytechnic)," Ind. Res. Work. Natl. Semin. 2012, vol. 2, no. 8, pp. 217224, 2012.

[3] A. Nugroho and D. Maulana, "Implementation of Fuzzy Mamdani in the Selection of New Student Admissions," Pelita Teknol., vol. 15, no. 1, pp. 13-18, 2020.

[4] A. A. Wulandari, M. Yusuf, V. B. R. Utamy, and Y. A. Permana, "New Student Admission System Using Fuzzy Logic Applications in the Matlab Toolbox," Maj. Ilm. UNIKOM, vol. 18 , no. 1, pp. 17-22, 2020, doi: 10.34010/MIU.V18I1.3826.

[5] Juhardi, Ilhamsyah, and S. Rahmayudha, "New Student Admission Decision Support System Using the Fuzzy Tsukamoto Method (Case Study: Yarsi Pharmacy Academy, 
Pontianak)," J. Komput. dan Apl., vol. 09, no. 01, pp. 23-32, 2021.

[6] W. Liang, M. Goh, and Y. M. Wang, "Multiattribute group decision making method based on prospect theory under hesitant probabilistic fuzzy environment," Comput. Ind. Eng., vol. 149, no. August, p. 106804, 2020, doi: 10.1016/j.cie.2020.106804.

[7] Fajar Rohman Hariri, "Application of the Fuzzy Sugeno Method in New Student Registration at SDN Sonopatik 1 Nganjuk," Tek. Inform. Univ. Nusant. PGRI Kediri, vol. 3, no. 1, pp. 41-46, 2016.

[8] J. Handoyo, "Design and Build a Decision Support System for the Selection of New Students with the Fuzzy Tahani Method (Case Study at SMK Migas Cepu)," SIMETRIS, vol. 10, no. 1, pp. 1-8, 2016.

[9] R. Firmansyah, "Fuzzy Decision Support System (FDSS) For New Student Admission Selection," Indones. J. Comput. Inf. Technol., vol. 2, no. 1, pp. 17-25, 2017.

[10] F. R. Hariri, "Application of the Fuzzy Sugeno Method in New Student Registration at SDN Sonopatik 1 Nganjuk," Nusant. Eng., vol. 3, no. 1, pp. 41-46, 2016.

[11] H. Jiang and B. Q. Hu, "A decision-theoretic fuzzy rough set in hesitant fuzzy information systems and its application in multi-attribute decision-making," Inf. Sci. (Ny)., vol. 579, pp. 103-127, 2021, doi: 10.1016/j.ins.2021.07.094.

[12] L. A. Zadeh, "Fuzzy Sets * -," Inf. Control, vol. 8, no. 3, pp. 338-353, 1965, doi: https://doi.org/10.1016/S00199958(65)90241-X.

[13] E. P. Astuti, R. Y. Purwoko, and M. W. Sintiya, "Ethnomathematical Forms in Adipurwo Batik in Number Pattern Learning," J. Math. Sci. Educ., vol. 1, no. 2, pp. 1-16, 2019, doi: 10.31540/jmse.v1i2.273.
[14] G. Cao, Y. Duan, J. S. Edwards, and Y. K. Dwivedi, 'Understanding managers' attitudes and behavioral intentions towards using artificial intelligence for organizational decision-making," Technovation, vol. 106, p. 102312, 2021, doi: 10.1016/j.technovation.2021.102312.

[15] T. Pangaribowo, "Implementation of Fuzzy Logic Algorithm in the Selection Process for New Student Admissions (Applied at Kotabaru Polytechnic)," SINERGI, vol. 18, no. 1, pp. 53-60, 2014.

[16] R. Rahim, "Prediction of landing and takeoff of aircraft based on the weather using fuzzy logic," IJAST, vol. 28, no. 20, pp. 409$415,2019$.

[17] M. Kirişci and N. Şimşek, "Decision making method related to Pythagorean Fuzzy Soft Sets with infectious diseases application," $J$. King Saud Univ. - Comput. Inf. Sci., no. xxxx, 2021, doi: 10.1016/j.jksuci.2021.08.010.

[18] W. Pratiwi, A. Sofwan, and I. Setiawan, "Implementation of fuzzy logic method for automation of decision making of boeing aircraft landing," IAES Int. J. Artif. Intell., vol. 10, no. 3, pp. 545-552, 2021, doi: 10.11591/ijai.v10.i3.pp545-552.

[19] L. A. Lindquist et al., "Rationale and study design for decision making \& implementation of aging-in-place/long term care plans among older adults," Contemp. Clin. Trials Commun., vol. 22, no. September 2020, p. 100756, 2021, doi: 10.1016/j.conctc. 2021.100756 .

[20] T. K. Paul, M. Pal, and C. Jana, "Multiattribute decision making method using advanced Pythagorean fuzzy weighted geometric operator and their applications for real estate company selection," Heliyon, vol. 7, no. 6, p. e07340, 2021, doi: 10.1016/j.heliyon.2021.e07340. 